\title{
MARXISMO Y FILOSOFía DE LA VIDA: LAS REFLEXIONES tempranas de Siegfried Kracauer sobre la Revolución Rusa y los Comienzos de LA UNIÓN SOVIÉTICA
}

\section{Marxism and Philosophy of life: The Early Reflections of Siegfried Kracauer on the Russian Revolution and the Beginnings of the Soviet Union}

\begin{abstract}
RESUMEN El artículo analiza las reflexiones tempranas de Kracauer sobre la Revolución Rusa de octubre de 1917, sobre la figura y la significación de Lenin y los primeros años de la Unión Soviética. Destaca las "afinidades electivas" que el ensayista alemán encuentra entre sus propios puntos de vista y el "método" de Lenin y Trotski pone estas reflexiones en relación con la obra posterior de Kracauer.
\end{abstract}

Palabras CLAVE: FILOSOFÍA DE LA VIDA. MARXISMO. ReVOlUCIÓN RUSA. UNIÓN SOVIÉTICA.

ABSTRACt The article analyzes Kracauer's early reflections on the Russian Revolution of October, 1917, on Lenin's figure and signification and on the first years of the Soviet Union. It underlines the "elective affinities" that the German essayist discovers between his own point of view and the "method" of Lenin and Trotzki, and put these reflections in relation with Kracauers' later work.

KEY-WORDS: PHILOSOPHY OF LIFE. MARXISM. RUSSIAN REVOLUTION. SOVIET UNION.

I

Igunos indicios acerca de las tempranas posiciones de Kracauer frente a la revolución de octubre y los comienzos de la Unión Soviética pueden extraerse de un manuscrito redactado en respuesta al certamen de ensayos anual lanzado por la Moritz-Manheimer Stiftung, cuyo tema para el año 1919 eran las siguientes preguntas: ¿Están ligados el amor al prójimo, la justicia y la tolerancia a una forma de Estado particular; y qué forma estatal ofrece la mejor garantía para la realización de aquellos? Asentado en perspectivas recurrentes en la Kulturkritik alemana de comienzos del siglo XX, el escrito presentado por Kracauer al certamen muestra una particular fusión de motivos extraídos de la filosofía de la vida simmeliana y de ideas procedentes del arsenal teórico
Miguel Vedda Facultad de Filosofía y Letras Univ. de Buenos Aires Buenos Aires. Argentina

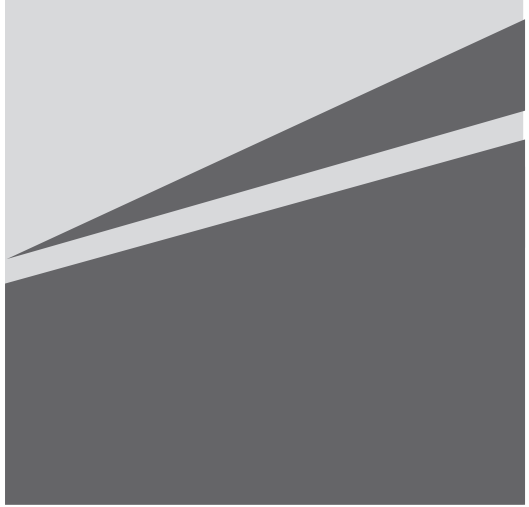


y publicístico de los movimientos socialistas contemporáneos - incluyendo entre ellos en primera línea al leninismo, como lo entendía entonces el ensayista alemán -. El autor del escrito no es un intelectual de observancia leninista ( $y$, de hecho, se ocupa de señalar las limitaciones que percibe en los defensores a ultranza de dicha concepción), pero a cambio se empeña en poner de relieve la innegable vigencia de la teoría y la praxis promovidas por el líder bolchevique.

El punto de vista - pretendidamente superador - desde el cual son analizadas las propuestas de Lenin es una concepción organicista, vitalista de la sociedad según la cual todas las culturas recorren un proceso de crecimiento, institucionalización, decadencia cultural y extinción; y este proceso posee un carácter inevitable: incluso en una comunidad cargada de un espíritu virtuoso, el orden inicialmente ideal tiene que fosilizarse en un desarrollo totalmente natural. Las imágenes de las que echa mano una y otra vez el autor del escrito para explicar esta evolución son las de una osificación (Verknöcherung) o una arterioesclerosis (Arterienverkalkung) de la vida social, ligada al triunfo de la burocratización y la rutina frente a las tendencias creativas, innovadoras que habían dominado en los períodos "juveniles" de la comunidad. Característico del aristocratismo del joven Kracauer es el hecho de que atribuya el triunfo de la rutina, la esclerosis de las instituciones públicas y la decadencia ética general a la acción de los sectores "bajos" de la sociedad, cuya influencia no pueden neutralizar indefinidamente los "grandes" líderes espirituales:

Los profetas del Antiguo Testamento, Cristo, Francisco de Asís y como quiera que se llamen todos los grandes líderes de la humanidad, una y otra vez intentaron liberar las almas y elevarlas a Dios; pero continuamente han vuelto los seres humanos, con insignificantes excepciones, a recaer en su posición intermedia habitual [...]. Es pre- ciso contar con que la persistencia en un nivel ético medio es el estado natural y normal de cualquier comunidad humana, y con que se requiere ya de un esfuerzo especial y de una ocasión especial para sacarla alguna vez de ese estado durante un corto tiempo.

Esta legalidad sociológica debería explicar por qué aun una forma estatal de ejemplar justicia se echa a perder a fin de cuentas y se introduce en ella un espíritu "inferior"; a este proceso de petrificación se suman las "necesidades sociológicas" que se explican a partir de una "solidificación del nivel ético medio; de un comportamiento humano, demasiado humano que es típico de la masa de los hombres y que por ende condiciona el destino de todo el grupo". ${ }^{2}$ Con el transcurso del tiempo, la comunidad se torna cada vez más indiferente hacia el fundamento de su vida, cada vez se relaja más el elevado espíritu ético a partir del cual pudo ser creado antaño el orden social:

En su lugar aparece la constitución normal del alma de los numerosos poco dotados, que poco a poco van llenando las instituciones con su propia esencia. Seguramente, no son en su mayoría malvados esos seres humanos, pero les falta también la fuerza de resistencia frente al mal, y no se oponen sin más a las circunstancias universales corrompidas cuyo producto son ellos mismos. ${ }^{3}$

El anhelo de amor al prójimo, justicia y tolerancia mencionado en la convocatoria del certamen es considerado como una cualidad propia de una comunidad cuyo orden (Ordnung) social y estatal ha alcanzado su último estadio y que sufre la arterioesclerosis. En tales circunstancias, aquellos que predican el

KRACAUER, 2004, p. 111. Donde no se indica algo diverso, las traducciones son mías.

Ibid., p. 112.

lbid. 
ideal de humanidad lo hacen para contrarrestar la osificación creciente y con ese propósito predican el regreso a los fundamentos iniciales del orden, a la esencia ética de este; invocan aquel estado que Kracauer designa como ursittlich (protoético) y en el que el espíritu de las instituciones emanaba inmediatamente del ethos de la comunidad. Pero, por decadentes que sean estas circunstancias, a partir de la agudización de estas brotan los gérmenes de lo nuevo; en tales épocas de conmoción, se resquebraja la costra de las convenciones y rutinas que paralizan la creatividad. Entonces se produce "el derrocamiento revolucionario de la vieja constitución, y ahora se inicia una era en que el ethos del pueblo logra inmediatamente manifestarse o puede lograrlo. Todo lo bueno que vive en los seres humanos emerge durante esta época de conmoción y busca expresarse e imponerse". ${ }^{4}$ Más allá de un vitalismo y un juvenilismo que estaban en boga en la época de redacción del escrito, en este se expresa una de las convicciones de más dilatada presencia en la obra de Kracauer: la de que las visiones del mundo poseen su mayor eficacia y validez cuando se hallan in statu nascendi; 5 todavía se la encuentra sostenida de manera enfática en el tratado póstumo sobre la historia.

En el estudio de 1919, da la ocasión para introducir un ejemplo que formará pendant con el bolchevismo: el de las comunidades cristianas primitivas; presentadas expresamente como comunistas, estas estaban movidas ante todo, de acuerdo con Kracauer, por un impulso ético. Como al joven Lukács unos años atrás, durante la ocupación con el "proyecto Dostoievski", 6 a Kracauer le preo-

\footnotetext{
Ibid., p. 117.

5 Ingrid Belke subraya que, al afirmar que "todas las exigencias morales y los movimientos sociales solo se corresponden con el ethos de la comunidad in statu nascendi, en el momento de su génesis", Kracauer lo hace en consonancia "con su maestro Georg Simmel” (BELKE, 1989, p. 20).

6 La expresión "Proyecto Dostoievski” ha sido empleada por Andreas Hoeschen para designar un corpus de textos que documentan la recepción lukácsiana de la obra del escritor ruso. Los primeros textos (1911) fueron escritos durante el "período ensayístico"; los
}

cupa examinar el proceso por el cual la fe a la vez ingenua y renovadora de los primeros cristianos se convirtió en ecclesia militans para degenerar luego en ecclesia triumphans. Llamativo es el hecho de que, Ilegada a este punto la argumentación, Kracauer corrija su tesis inicial sobre la necesaria y "natural” esclerosis de las instituciones para diseñar una alternativa de índole utópica: la propuesta de una revolución permanente capaz de mantener a la comunidad en un estado de agitación continua, de modo que las convicciones creadoras y vitales se mantengan activas y fecundas y se resistan a toda consolidación; de modo que los órdenes se recreen una y otra vez sin osificarse. De ahí que se afirme que existe un único medio para preservar la existencia estatal de una comunidad siempre a la altura de las exigencias éticas: revolucionar esa existencia. Kracauer, que en este punto se apoya intensa y explícitamente en Gustav Landauer, afirma que lo único que debería petrificarse en sistema, en un pueblo vivo y emancipado, es la carencia de sistema.

La "revolución eterna" (ewige Revolution) que promueve el ensayo demanda que se organicen "las ilegalidades para que lo legal no desborde; que se piense, por ejemplo, a propósito de cada institución que ha de fundarse, en la dinamita que está destinada a

\footnotetext{
últimos (1918-1919), durante la revolución húngara. Entre el conjunto de escritos se destacan Teoría de la novela y las anotaciones para el libro sobre Dostoievski que Lukács no llegó a escribir. Cabe recordar aquí que, no menos que en Lukács, el entusiasmo de Kracauer por la Rusia contemporánea estaba intensamente coloreado por el impacto que en él habían producido las novelas de Dostoievski. Un buen testimonio de la interpretación "dostoievskiana" de la realidad rusa que hace el ensayista frankfurtiano es el artículo “Nietzsche y Dostoievski” (1921). Jörg Später señala acertadamente: "Como tantos otros que admiraban el carácter originario de los seres humanos naturales y espirituales de Rusia, también Kracauer se sumó al culto de Dostoievski [...]. En su fanatismo por Rusia, el Kracauer de 1920 no se distinguía de intelectuales tan diferentes como Rainer Maria Rilke u Oswald Spengler, que sufrían Occidente" (SPÄTER, 2016, p. 57). La última observación, sin embargo, es desmedida, por cuanto no percibe los gérmenes revolucionarios presentes en Kracauer y básicamente ausentes en otros los dos autores mencionados.
} 
hacer explotar; de lo contrario, junto con las grandes pasiones se extinguen también las grandes virtudes".7 El autor del escrito está persuadido de que los seres humanos "solo son verdaderamente buenos cuando viven sobre un volcán. Es posible concebir la genuina revolución como la manifestación elemental del espíritu ético, oculto durante mucho tiempo, de una comunidad". ${ }^{8}$

Puede verse que los esquemas fatalistas solo son planteados de manera taxativa cuando se habla del pasado; en cuanto el centro del escenario es ocupado por las preocupaciones del presente, la descripción del reino de la necesidad (sociológica) es relevada por la propuesta de interrumpir el continuum histórico precedente e introducir a las comunidades humanas en el venturoso reino de la libertad. Aquí es donde entran en consideración los ideales y las políticas de Lenin y el partido bolchevique. Kracauer piensa que el socialismo es la única posibilidad actualmente válida para superar ese estado de petrificación mortal de todas las fuerzas vitales en el que ha sumido a los hombres el capitalismo. Pero su interés está menos puesto en destacar la oportunidad histórica que el comunismo posee de crear por primera vez un estado de revolución eterna, capaz de sustraer a las comunidades indefinidamente a los procesos de osificación y muerte, que en destacar aquellos riesgos de burocratización que, de acuerdo con el autor, son específicos del socialismo. Más allá de su orientación kulturkritisch, algunas de las observaciones resultan premonitorias. Kracauer supone que, con el avance de los procesos de socialización, la

\footnotetext{
KRACAUER, 2004, p. 122.

8 Ibid., p. 119. Afirmaciones como esta, que recorren todo el escrito, justifican que no estemos de acuerdo con la aseveración, formulada por Olivier Agard en su excelente libro sobre Kracauer, de que si bien "Kracauer se interesa en la idea revolucionaria y es un observador atento de la revolución soviética, uno tiene a veces la sensación de que este interés está guiado por una filosofía de la cultura globalmente conservadora en cuanto a sus valores, su ideal es [... ] una sociedad dominada por las tradiciones y fundada en la autoridad, una Gemeinschaft tradicional" (AGARD, 2010, p. 47).
}

vida podría racionalizase de manera creciente y los seres humanos convertirse en funcionarios de la comunidad. El socialismo requerirá necesariamente de abundantes organismos de control y solo los aspectos insignificantes de la vida quedarán librados al azar; el principio del orden podría asumir una función tiránica y constituirse en correlato del dominio tiránico del intelecto sobre los principios vitales. Entonces podría correrse el riesgo de que el socialismo asfixie la vida; de que, así como la socialización de la sociedad (Sozialisierung der Gesellschaft) es hoy un mandamiento de justicia, con igual certeza conduzca mañana a la atrofia de la ética auténtica:

En la medida en que se intenta eliminar por todas partes las callosidades, suprimir arbitrariedades, se restringe la esfera de la acción individual espontánea de manera considerable y se asfixian las fuerzas motrices del alma, que anhelan un desarrollo sin inhibiciones. La maquinaria administrativa se amplía, el número de las prescripciones crece constantemente, se toman cada vez más precauciones a fin de asegurar nuestra existencia. ${ }^{9}$

Por esto es preciso que la sociedad socialista esté a cada momento dispuesta a revisar los fundamentos de su propia existencia; que se realicen todos los esfuerzos a fin de mantener a dicha sociedad permanentemente in statu nascendi. En el marco de estas reflexiones se sitúan las reflexiones en torno a Lenin: en este cree descubrir Kracauer una mezcla de genialidad y simplicidad, de lucidez intensa e ingenuidad, en virtud de la cual, por un lado, afirma que es preciso reconocer la plena justificación histórica de las ideas del líder bolchevique desde el punto de vista de la eticidad pura y, por otro, ve en las perspectivas leninianas un riesgo de osificación burocrática. Curiosamente, el ensayista imagina que Lenin escribe y actúa, no sobre la base

9 KRACAUER, 2004, p. 121. 
de principios teóricos, sino de intuiciones de orden instintivo. Kracauer se apoya en el escrito "Las próximas tareas de la República Soviética” de Lenin para atribuir a este el pensamiento de que la osificación de un orden es la causa de una nueva injusticia; por otro lado, el líder bolchevique se protege con furiosa energía del proceso de burocratización,

cuyo surgimiento es siempre una señal inequívoca de que una comunidad comienza a adaptarse a un orden. Este proceso es combatido por Lenin, entre otras cosas, logrando la revocabilidad en cualquier momento de los funcionarios y concediendo a los sóviets el derecho de control continuo de todas las medidas legislativas. Puede verse que se trata, en última instancia [...] de producir una revolución duradera, de generar intencionalmente un estadio de continua tensión y atención en la que la comunidad esté dispuesta a revisar a cada instante los fundamentos de su existencia. ${ }^{10}$

Esta preocupación sobre el futuro próximo del bolchevismo conduce a una serie de reflexiones sobre la pedagogía. Kracauer cuestiona la educación de los estudiantes dentro del marco del orden vigente, cuyo propósito es transformar a jóvenes independientes en ciudadanos que aceptan sin objetarlas las instituciones nacionales y que son demasiado sedentarios, en sus pensamientos y sentimientos, como para cuestionar el statu quo. Exponentes señalados de este modelo son los paradigmas educativos de la Alemania guillermina, cuyo objetivo es guiar metódicamente a la juventud al enaltecimiento del orden estatal, que desdeñan cualquier crítica a los fundamentos y que produjeron una generación de arribistas incapaces de impedir la osificación del espíritu comunitario. A contrapelo de este modelo, de lo que se trata es de "criar revolucionarios que se subleven contra

$10 \quad$ Ibid., p. 123. el orden en el que han crecido; seres humanos de la rebelión, que se niegan a continuar simplemente allí donde se ha estancado la generación precedente"; "11 si se ansía impedir la esclerosis, es necesario infundir en la generación venidera el espíritu de la rebelión: "La misión de los seres humanos especialmente dotados para ello consistirá en ser educadores para la conmoción y preparadores de nuevos órdenes". ${ }^{12}$ De manera tácita pero perceptible, quería alcanzar el autor del escrito el propósito de que los líderes políticos de la época comprendieran y aplicaran esta demanda de los líderes espirituales; dicho de otro modo: que Lenin oyera y pusiera en práctica las sugerencias del joven Kracauer.

\section{II}

El autor del ensayo de 1919 no es, como dijimos, un marxista; es a lo sumo un crítico de la cultura (capitalista) que querría ver aprovechadas para sus propios objetivos las herramientas de un leninismo que le es parcialmente afín, pero con el que no se siente identificado de manera plena. No querría tanto subordinarse al leninismo como ver a este sometido a sus propias perspectivas teóricas. La ocupación intensa con la obra de Marx y la aproximación al marxismo tienen lugar, en Kracauer, a mediados de la década de 1920; cabe recordar que, a contrapelo de otras relecturas contemporáneas de la obra marxiana - de manera particular, la realizada por el Lukács de Historia y conciencia de clase (1923) -, el ensayista de Frankfurt no ve en el materialismo histórico la continuación y superación del idealismo alemán, sino una prosecución de la filosofía materialista francesa. En carta a Bloch del 29 de junio de 1926, Kracauer destaca que "categorías decisivas del marxismo, como, por ejemplo, su concepto de 'ser humano' o de 'moral' [... ] solo pueden ser comprendidas si, por así decirlo, se cava un túnel que, pasando por debajo del macizo montañoso Hegel, vaya de Marx a, por ejem-

\footnotetext{
Ibid., p. 125 .

2 Ibid., p. 126.
} 
plo, Helvetius". ${ }^{3}$ Puede entenderse que, en el contexto de esta transformación, las posiciones del autor hayan ido alejándose de la abstracción por momentos enigmática de los primeros escritos y aproximándose de manera más concreta a la realidad contemporánea. Este cambio de perspectivas no se tradujo en análisis específicos de las circunstancias soviéticas; circunstancias que, sin embargo, Kracauer seguía con atención, según puede deducirse de los libros, conferencias y filmes reseñados. De los artículos dedicados a estas cuestiones es posible extraer algunas perspectivas respecto de las condiciones sociohistóricas y políticas rusas, así como acerca del "marxismo soviético". Nos ocuparemos aquí de algunos análisis que estimamos especialmente representativos y que fueron publicados en su mayoría entre 1931 y 1933, en tiempos de consolidación del stalinismo en la URSS y de ascenso del nazismo en Alemania. Durante esos años se desarrolló un intenso debate en torno a la figura y la función del intelectual; en él interviene Kracauer con una serie de artículos vinculados con su apuesta a favor de la creación de una opinión pública ilustrada y democrática (ante todo, entre las clases medias) que funcione como alternativa frente a la creciente fascistización de Alemania. La segunda novela del autor, Georg, escrita entre 1930 y 1934 pero publicada póstumamente, muestra el colapso del proyecto en estrecha relación con una traición de los intelectuales que aparece configurada en un tono predominantemente satírico. Este tono aparece de momentos en los ensayos dedicados al tema; pero en ellos aún se nota la voluntad de influir sobre un público lector susceptible de ser sustraído a perspectivas que el autor considera cuestionables o problemáticas. Los artículos "Was soll Herr Hocke tun?” (¿Qué debe hacer el señor Hocke?), ${ }^{14}$ "Über den Schriftsteller" (Sobre el escritor) ${ }^{15} \mathrm{y}$, sobre todo, "Minimal-

13 BLOCH, 1985, v. 1, p. 282. Cf., sobre la asimilación de la obra de Marx por parte de Kracauer, MÜLDER-BACH, 1985, p. 56-60.

14 Publ. en la Frankfurter Zeitung el 17/4/1931.

15 Publ. en Die Neue Rundschau 1/6, año 42 (junio de 1931). forderung an die Intellektuellen" (Petición mínima a los intelectuales) ${ }^{16}$ ofrecen referencias específicas sobre las posiciones del ensayista por aquellos años; en ellos puede verse el interés en determinar la ubicación de la intelectualidad alemana. Los heterogéneos miembros de esta última cultivan una riesgosa ignorancia acerca de su situación y buscan, de manera regresiva, un lugar de refugio: "Muchos se entregan ciegamente a la reacción; algunos, en su pasaje al movimiento obrero, sacrifican perniciosamente sus sólidos conocimientos y están además [...] los que no tienen ninguna noción de lo que está sucediendo. ${ }^{17}$ En relación con la intelectualidad soviética y sus influencias sobre la alemana, es el segundo de los casos indicados el que más preocupa a Kracauer; ante todo, porque este ve en el sometimiento de las reflexiones a la línea partidaria un sacrificium intellectus de devastadores para los intelectuales particulares y para el íntegro edificio del marxismo. En los ensayos de la época, Kracauer insiste en vincular al materialismo histórico con un cuestionamiento concluyente de todos los dogmas y saberes establecidos; lo que exige de los intelectuales revolucionarios es que "pongan radicalmente en duda todas las posiciones dadas. Es decir, deben confrontar sus conceptos heredados, y precisamente los que son en apariencia inconmovibles, con los resultados de la teoría revolucionaria, y luego dar cuenta sobre la realidad concreta que preservan aquellos conceptos". ${ }^{18}$ La solidaridad genuina del intelectual con la causa del socialismo no puede consistir en una repetición de fórmulas - lo que podría representar una continuación de las osificaciones y esclerosis consideradas en el ensayo de 1919 -, sino en una continua revisión de las herramientas de pensamiento, en vista de que la "afirmación rígida, adialéctica de los ideales socialistas enumerados degenera fácilmente en sabotaje del socialismo" y "los intelectuales que ceden ante lo dado,

\footnotetext{
Publ. en Die Neue Rundschau 2/7, año 42 (julio de 1931). KRACAUER, $1990 \mathrm{e}$, p. 307.

KRACAUER, 1990c, p. 354.
} 
deponen sus armas ante una utopía". ${ }^{19}$ En un sentido similar avanzan las críticas a la colectivización y proletarización de los intelectuales promovidas por ideólogos soviéticos y, con un radicalismo aún mayor, por algunos de sus seguidores alemanes. A contrapelo de estas propuestas, Kracauer piensa que el intelectual solo "como individuo (o, en el mejor de los casos, asociado con quienes piensan de manera similar) puede, por ahora, destruir la falsa conciencia, preparar una correcta y cumplir todas las otras funciones decisivas que le plantea la sociedad actual". ${ }^{20}$

En este marco deberían entenderse los comentarios de Kracauer sobre las conferencias dictadas en Alemania por Sergei Tretiakov y Anatoli Lunatcharski. Del primero se ocupa en "Instruktionsstunde in Literatur" (Clase de literatura), ${ }^{21}$ cuyo título indica ya una posición irónica que domina en buena parte del artículo. Kracauer evalúa desde una distancia crítica y aun satírica el modo en que el suboficial Tretiakov ordena deshacerse de fetiches tales como los de "individualidad", "talento" e "inspiración" para, a cambio, promover otros no menos riesgosos, como el de

un modo de considerar el mundo que quizás sea útil para el plan quinquenal ruso, pero que no está a la altura de la conciencia europea y no tiene nada que ver con el marxismo. Me refiero a que habría que resguardar a Marx, que en definitiva también procede de la llustración francesa e inglesa, de una sucesión que no deforma al materialismo dialéctico menos que a las posiciones opuestas. $^{22}$

Algo más matizados son los comentarios respecto de la colectivización. Por un lado, Kracauer cuestiona la determinación de imponerles a los escritores el anonimato

19 Ibid., p. 354.

$20 \quad$ KRACAUER, $1990 e$, p. 346.

21 Publ. en la Frankfurter Zeitung el 26/4/1931, p. 306308.

$22 \quad$ KRACAUER, 1990b, p. 309. y conducirlos coactivamente a la praxis insertándolos - como se tornó usual desde 192728 - en las fábricas o en los colectivos rurales, lo cual, según Tretiakov, representaría una forma legítima de cerrar la grieta entre arte y vida. No menos cuestionables le parecen los intentos de compensar esta proletarización de los literatos con una literaturización de los proletarios, basados en la fe ingenua en que, en el futuro, cualquier integrante de la sociedad comunista podrá ser simplemente un escritor. Pero, por otro lado, el autor del artículo celebra la determinación de Tretiakov de condenar "la arrogancia con la que muchos así llamados escritores libres se elevan a sí mismos por encima de la existencia de los periodistas, aunque en la mayoría de los casos habrían hecho mucho mejor si hubieran aprendido a disciplinarse en un diario". ${ }^{23}$ Kracauer estima que a ningún literato podría perjudicarlo la realización de una actividad práctica; antes bien, habría que celebrar quizás que esta actividad lo libere de las veleidades del escritor profesional. Publicado diez meses más tarde, "Der 'operierende' Schriftsteller" (El escritor "operativo") 24 ofrece un comentario de tonos menos satíricos y más mesurado; la ocasión está dada por la publicación en alemán de un libro de Tretiakov. Una diferencia importante respecto del artículo anterior es el hecho de que el autor de la reseña declara saber ahora que la política cultural del "grupo Tretiakov", que defienden una posición de "extrema izquierda", no se encuentran "de ningún modo en consonancia con la opinión oficial del Partido". ${ }^{25}$ Si anteriormente se había presentado a Tretiakov como a un suboficial del stalinismo, ahora parece tenerse, al menos, la conciencia de que existe un "desacuerdo" que, a la postre, concluirá con la condena y ejecución del escritor, teórico y militante en 1937. Llamativo es que ahora el cuestionamiento del modelo de escritor trazado por Tretiakov importa mucho menos aún que la crítica del estado de cosas vigente en Alema-

\footnotetext{
Ibid., p. 310.

24 Publ. en la Frankfurter Zeitung el 17/2/1932, p. 126-128.

25 KRACAUER, 1990a, p. 27.
} 
nia. De ahí que se afirme, en relación con las propuestas colectivistas, que operaciones literarias acordes con los modelos rusos no son de momento posibles en Alemania; pero, de todos modos, los empeños de Tretiakov podrían estimular a algunos de nuestros literatos para que revisen alguna vez con rigor su relación con la praxis. Esta relación es, en la mayoría de los escritores alemanes, una relación errada:

Se describe la realidad concreta, en lugar de rastrear sus defectos de construcción; se busca una evasión en lo estético y se evita movilizar las fuerzas orientadas a la acción; se cultiva la metafísica, donde habría que ingresar en la economía, etc. [...] El libro de Tretiakov podría al menos llamar la atención de muchos autores sobre cómo habría que entender, en realidad, la áspera fusión de teoría y praxis. ${ }^{26}$

El ensayo "Lunatcharski über die russische Kultur" (Lunatcharski sobre la cultura rusa $)^{27}$ continúa la línea de análisis a la vez crítica y satírica del primer artículo sobre Tretiakov. Enfocado nuevamente en destacar la relevancia de la discusión en Alemania, Kracauer cuestiona tanto el modelo colectivista como la obstinación de los escritores alemanes en sostener posiciones idealistas, contrapuestas a la praxis. Un aspecto original del artículo es la tesis según la cual el comunismo representa una doctrina de salvación secularizada: para intelectuales-funcionarios como Lunatcharski, el estado actual en la URSS es el del socialismo combatiente (acorde con la ecclesia militans), una época heroica en que varias generaciones deberán sacrificarse en función de un futuro que pertenecerá al socialismo consumado (la ecclesia triumphans). Puede entenderse que un pensador tan identificado con el dinamismo y tan hostil al sedentarismo social e intelectual - adecuadamente ha definido Enzo Traverso a

26 Ibid., p. 27.

27 Publ. en la Frankfurter Zeitung el 6/11/1931, p. 827-829.
Kracauer como un intelectual nómada - tenía que sentirse importunado ante el empeño de Lunatcharski en definir al socialismo consumado como "el reino de la paz y la libertad, como un estado sin luchas que ya no conoce evolución alguna. Es el Paraíso mismo, el terrenal estar más allá del tiempo". ${ }^{28}$ La concepción plenamente dinámica de la vida actual es puesta en movimiento en función de una "estática según la cual la existencia humana tiene un valor incomparable porque se relaciona con contenidos que remiten más allá de la evolución en el tiempo". ${ }^{29}$

Hasta aquí, en los análisis sobre la política cultural soviética predominan los tonos negativos, y cabría preguntarse si existe una figura capaz de proveer una contraparte positiva en el cuadro trazado por Kracauer. Sugestivamente, esta función es cumplida por Trotski, a quien ya había dedicado conceptos elogiosos el pensador alemán en su importante ensayo "La biografía como forma artística de la nueva burguesía", ${ }^{30}$ donde se destaca el empeño del líder bolchevique en asimilar con franqueza, en su biografía, la nueva realidad del capitalismo del siglo $X X$, sin refugiarse regresivamente en un individualismo anacrónico, arcaico. Según Kracauer, aquello a lo que se concede forma en la autobiografía de Trotski es

a un individuo diferente de aquel al que se refiere la literatura burguesa. Un individuo que ya ha cumplido la transición, en la medida en que solo se hace real a través de su transparencia frente a la realidad, y no en la afirmación de su propia realidad. Un individuo nuevo, fuera de la atmósfera brumosa de las ideologías: existe exactamente en la medida en que él mismo se ha suprimido en interés de las actuales necesidades reconocidas. ${ }^{31}$

2 KRACAUER, 1990a, p. 397.

9 Ibid., p. 397.

Publ. en la Frankfurter Zeitung el 29/6/1930; incorporado luego a la compilación El ornamento de la masa.

31 KRACAUER, 1006, p. 315. 
Aún más relevantes para nuestro tema son las ideas desarrolladas en el artículo "Oktoberrevolution. Revolutionärer Realismus", 32 dedicado a comentar la edición alemana del segundo volumen de la Historia de la Revolución Rusa. Para el autor de este artículo, Trotski no es el representante de una tendencia separada, particular dentro del movimiento comunista, sino el exponente por excelencia del marxismo dentro del escenario político ruso, en contraposición con el disciplinamiento y el mecanicismo de los representantes de la línea oficial. Esto no implica que deba verse en Kracauer a un trotskista tout court; lo que el ensayista advierte es más bien una afinidad electiva entre el método del líder e intelectual ruso y sus propias concepciones del marxismo. De ahí que afirme que la exposición de Trotski en la Historia de la Revolución Rusa

se desarrolla totalmente sobre la base del materialismo histórico, que ciertamente, desde los tiempos de Marx, nunca había sido aplicado a tal gran escala y con semejante sentido de la realidad. Trotski no lo emplea para hacer simplificaciones propagandísticas del proceso histórico, como es usual en el marxismo vulgar, sino que torna evidente la validez de las interpretaciones materialistas en el propio material concreto. En lugar de aproximarse a la materia partiendo de fetiches conceptuales, muestra las legalidades que influyen sobre la empiria. ${ }^{33}$

Kracauer designa al método aplicado por Trotski no solo como marxista en el sentido más genuino, sino también como propiamente leninista, en la medida en que, más allá de toda originalidad personal, "se pega estrechamente a los talones de la realidad social de acuerdo con el interés revolucionario". ${ }^{34}$ La

32 Publ. en Deutsche Republik 7/19 (5/2/1933), p. 591-596.

33 KRACAUER, 1990d, p. 201.

34 Ibid., p. 202. afinidad que el escritor percibe con el líder se refuerza además por el hecho de que en la Historia de la Revolución Rusa encuentra una suerte de tertium datur superador entre las vastas construcciones abstractas, a las que se les escapa la empiria, y el análisis documental, que se pierde en la plétora de hechos particulares; es una metodología similar a la construcción en el material promovida por Kracauer y aplicada de manera ejemplar en el estudio Los empleados (1930). No menos importante es, para el autor de la reseña, la convicción genuinamente leninista de Trotski de que la revolución, por un lado, no puede hacerse desde arriba, sino que debe tener su punto de partida en las profundidades elementales de los ánimos de las masas; pero, por otro, requiere de la planificación, del más riguroso trabajo organizativo del partido, en oposición tanto al blanquismo como a la teoría luxemburguiana de la espontaneidad.

Pero Kracauer no está solo interesado en subrayar sus coincidencias teóricas y metodológicas con Trotski; también busca extraer, de la obra de este, algunos elementos útiles para dar cuenta de la actualidad alemana. Esto se advierte ante todo en los comentarios en torno a las reflexiones de Trotski sobre el comportamiento de las clases medias, en los que se resaltan importantes similitudes con las circunstancias que posibilitaron el ascenso del nazismo. Ante todo, se comenta el proceso por el cual la pequeña burguesía abandona cualquier simpatía por la revolución y busca sus salvadores en el bando enemigo al del proletariado. Sí, durante la pleamar, el proletariado arrastra consigo a los pequeñoburgueses, en la bajamar esta puede llevar hacia la reacción a estratos significativos de la clase trabajadora: esa es, según Trotski, y según Kracauer, la dialéctica de las olas comunistas y fascistas en la evolución europea de postguerra. No menos actual le parece el análisis del bonapartismo: un gobierno "que se arroga facultades dictatoriales para poner fin a la división de la nación y, al mismo tiempo, afirma encontrarse por encima de las clases". 35

35 Ibid., p. 204. 
La relevancia de estas consideraciones se percibe mejor cuando se piensa que Kracauer se apoyó en caracterización que hizo Marx del bonapartismo, no solo para fundamentar su "biografía social" (Gesellschaftsbiographie) de París en su libro sobre Offenbach (1937), sino aún más para sustentar su propia teoría y análisis del fascismo, como aparece desarrollada, ante todo, en Totalitäre Propaganda (La propaganda totalitaria, 1936-1938).

El método aplicado por Trotski en su Historia es denominado realismo revolucionario; una expresión que el propio líder soviético emplea para caracterizar a Lenin. $Y$ justamente a una defensa de este último está dedicada (por cierto: con los ojos de Trotski) la última sección del artículo. Más allá de todo un universo de divergencias, la imagen de Lenin que aquí se esboza tiene algunas semejanzas con la trazada por Lukács en su Lenin. Un estudio sobre la coherencia de su pensamiento (1924). El filósofo húngaro, en efecto, había presentado al mayor líder de la Revolución Rusa como una notable superación de la antítesis entre el principismo abstracto y la Realpolitik oportunista; Kracauer subraya que el proceder político de Lenin no es oportunismo, sino un realismo revolucionario que "se objetiva en el libro de Trotski y, a pesar de ciertos remanentes subjetivos, no es negado en ningún lugar". “ ${ }^{36}$ Es notorio que el autor del artículo - un "curioso realista" (Adorno) - se siente hondamente afín a esta modalidad de realismo, más allá de todas sus críticas y reservas frente al desarrollo del mundo soviético después de la revolución; no en vano concluye su comentario afirmando que "el provecho decisivo que el lector alemán podría extraer de la obra es ser afectado"37 por el realismo revolucionario que Kracauer encuentra y celebra en Lenin y Trotski, y cuya ausencia deplora en el ambiente cultural y político de la Alemania contemporánea.

36 Ibid., p. 205.

37 Ibid.

\section{Bibliografía}

AGARD, OLIVIER. Kracauer. Le chiffonnier mélancolique. París: CNRS, 2010.

BELKE, INGRID. "Siegfried Kracauer als Beobachter der jungen Sowjetunion”. In: KESSLER, MICHAEL; LEVIN, THOMAS Y. (eds.), Siegfried Kracauer. Neue Interpretationen. Tübingen: Stauffenburg, 1990, p. 17-38.

BLOCH, ENRST. Briefe 1903-1975. Ed. de Karola Bloch et al. 2 vols. Frankfurt/M: Suhrkamp, 1985. KRACAUER, SIEGFRIED. “Der 'operierende' Schriftsteller”. In: -, Schriften 5.1-3, vol. 3, p. 26-33 (1990a).

KRACAUER, SIEGFRIED. "Instruktionsstunde in Literatur. Zu einem Vortrag des Russen Tretjakov”. In: -, Schriften 5.1-3, vol. 2, p. 308-311 (1990b).

KRACAUER, SIEGFRIED. “Minimalforderung an die Intellektuellen”. In: -, Schriften 5.1-3, vol. 2, p. 352-356 (1990C).

KRACAUER, SIEGFRIED. “Oktoberrevolution. Revolutionärer Realismus”. In: -, Schriften 5.1-3, vol. 3, p. 201-205 (1990d).

KRACAUER, SIEGFRIED. Schriften 5.1-3. Ed. de Inka Mülder-Bach. 3 vols. Frankfurt/M: Suhrkamp, 1990.

KRACAUER, SIEGFRIED. “Über den Schriftsteller”. In: -, Schriften 5.1-3, vol. 2, p. 343-346 (1990e).

KRACAUER, SIEGFRIED. “Was soll Herr Hocke tun?”. In: -, Schriften 5.1-3. Ed. de Inka Mülder-Bach. 3 vols. Frankfurt/M: Suhrkamp, 1990, vol. 2, p. 301-308 (1990f). 
KRACAUER, SIEGFRIED. "Sind Menschenliebe, Gerechtigkeit und Duldsamkeit an eine bestimmte Staatsform geknüpft, und welche Staatsform gibt die veste Gewähr für ihre Durchführung? Eine Abhandlung”. En: -, Werke. Ed. de Inka Mülder-Bach e Ingrid Belke. Vol. 9: Frühe Schriften aus dem Nachlaß. Ed. de Ingrid Belke, con la colaboración de Sabine Biebl. Frankfurt/M: Suhrkamp, 2004, vol. 9.2, p. 78-136.

KRACAUER, SIEGFRIED. "La biografía como arte neoburgués”. In: -, Estética sin territorio. Edición y traducción: Vicente Jarque. Murcia: Colegio oficial de aparejadores y arquitectos técnicos de la región de Murcia, 2006, p. 309-315.

MÜLDER, INKA. Siegfried Kracauer - Grenzgänger zwischen Theorie und Literatur. Seine frühen Schriften 1913-1933. Stuttgart: Metzler, 1985.

SPÄTER, JÖRG. Siegfried Kracauer. Eine Biographie. Frankfurt/M: Suhrkamp, 2016.

\section{SOBRE O AUTOR}

\section{Miguel Vedda}

Prof. titular plenario de la cátedra de Literatura Alemana (UBA) e investigador principal del CONICET. Director de la cátedra libre "Teoría crítica y marxismo occidental” (UBA). Facultad de Filosofía y Letras - Univ. de Buenos Aires. Buenos Aires. Argentina.

E-mail: <miguelvedda@yahoo.com.ar>

Submetido em: 3-2-2018

Aceito em: 9-2-2018 